\title{
Lightning Response of Multi-Port Grids Buried in Dispersive Soils: An Approximation versus Full-wave Methods and Experiment
}

\author{
Seyyed Sajjad Sajjadi, Saeed Reza Ostadzadeh* \\ Engineering department, Arak University, Arak, Iran \\ *corresponding author, E-mail: s-ostadzadeh@araku.ac.ir
}

\begin{abstract}
In this paper, application of multi-conductor transmission line model (MTL) in transient analysis of grounding grids buried in soils with frequency-dependent electrical parameters (dispersive soil) is investigated. In this modeling approach, each set of parallel conductors in the grounding grid is considered as a multi-conductor transmission line (MTL). Then, a two-port network for each set of parallel conductors in the grid is then defined. Finally, the two-port networks are interconnected depending upon the pattern of connections in the grid and its representative equations are then reduced. Solving these simplified equations, the transient analyses of grounding grids is efficiently carried out. With the aim of validity, a number of examples previously published in literature are selected. The comparison of simulation results based on the MTL shows good agreement with numerical and experimental results. Moreover, in despite of numerical methods computational efficiency is considerably increased.
\end{abstract}

\section{Introduction}

The lightning performance of grounding systems plays a significant role in the safe and reliable operation of power networks $[1,2]$. This is because of the fact that lightning is the source of destruction in electrical installations, and its interference to electrical devices can cause malfunction or even destruction of sensitive electronic instrumentation. As a result, accurate design of grounding systems can lead to optimum design of lightning protection systems which, in turn, reduces tremendous loss.

Analysis and design of grounding systems is still a challenging task because of the complexity of soil electromagnetic characteristics due to dispersion and ionization. These effects can be treated separately or simultaneously using numerical methods either in time domain or in frequency domain. When soil dispersion is a prime concern, frequency-domain methods are preferred. These include the method of moments [?], the finite element method [12], and the hybrid electromagnetic method [13]. In contrast with the frequency-domain methods, time-domain methods are often used to treat the soil nonlinearity due to ionization $[14,15]$. A combined time-frequency domain method has been recently adopted to analyze grounding systems considering both dispersion and ionization of soil $[16,17]$.

All the above-mentioned methods are time-consuming and often require considerable computer resources, particularly in the case of large grounding grids. To tackle this issue, an efficient one-dimension transmission line method (TLM-1-D) has been proposed for transient analysis of grounding electrodes buried in ionized soils [18]. In this method, however, the coupling between parallel conductors is ignored, and the soil dispersion cannot be treated due to its time-domain nature. These issues have been overcome in the multi-conductor transmission line model where each set of parallel conductors in the grounding grid is modeled as a multi-conductor transmission line and are connected via appropriate two-port networks (MTL) [19]. The interconnection of the resultant cascaded two-port networks is configured according to the grid layout, and the respective governing equations are reduced to simplify computation of transient voltage and current at various grid junctions. With the use of this modeling approach, leakage currents into soil can also be readily determined by subtracting currents of the two cascaded junctions, and consequently, lightning-induced voltage on the soil surface is efficiently computed.

To show capability of the MTL, a number of grounding grids from published papers are selected and analyzed with the use of the MTL. In analyses, the electrical parameters of soil is assumed to be both constant (non-dispersive) and frequency dependent (dispersive). The MTL-based results show good agreement with the FEM, HEM and experimental results while the run-time is considerably reduced. In addition, to show more ability of approach, the single-port examples in case of multi-port are validated as well.

Finally, the lightning-induced voltage on the soil surface in different examples are computed and the effect of soil dispersion for the first time is investigated.

This paper is organized as follows. In section II, principles of the MTL is briefly explained. Section III is focused on validity of the MTL in transient analyses of grounding grids with and without considering dispersion of soil. In section IV, capability of the MTL in transient analyses of two-port grounding grids is given. Lightning-induced voltage on the soil surface with and without considering soil dispersion is also presented in section V. Finally, in section VI, concluding remarks are given. 


\section{Multi-Conductor Transmission Line Model}

In this section without losing generality, the modeling approach is applied on a grounding grid of size $1 \times 1$ as shown in figure 1 . In this figure, there are four conductors. With reference to [19], voltages and currents along each conductor at any point " $x$ " is computed via following equations describing propagation phenomenon

$$
\begin{aligned}
& -\frac{\mathrm{d}^{2}}{\mathrm{dx}^{2}} \mathrm{~V}=\mathrm{ZYV}=\mathrm{PV} \\
& -\frac{\mathrm{d}^{2}}{\mathrm{dx}^{2}} \mathrm{I}=\mathrm{YZI}=\mathrm{P}_{\mathrm{t}} \mathrm{V}
\end{aligned}
$$

where $\mathrm{Z}$ and $\mathrm{Y}$ represent, respectively, the series impedance and parallel admittance per unit length, I and $\mathrm{V}$ are, respectively, the phasor of current and voltage, $\mathrm{P}=\mathrm{ZY}$, $\mathrm{P}_{\mathrm{t}}=\mathrm{YZ}$ and $\mathrm{X}$ is the variable of the conductor length.

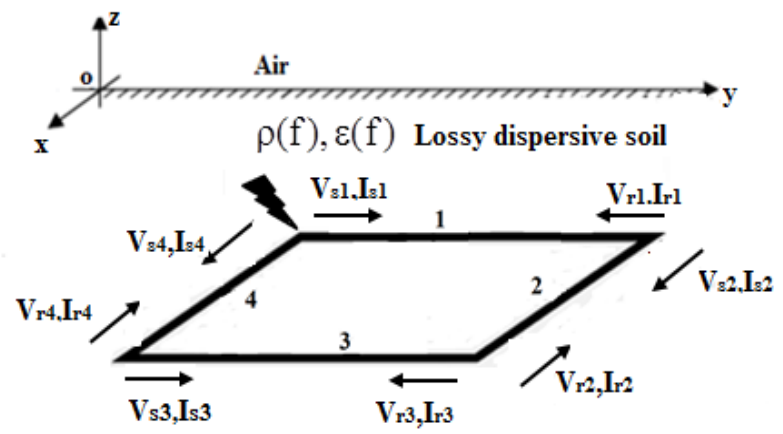

Figure 1: Schematic diagram of a grounding grid of size $1 \times 1$.

According to [19], via solving (1) and (2), voltage and current at sending and receiving points of each conductor is expressed as follows

$$
\begin{aligned}
& \mathrm{I}_{\mathrm{s}}=\mathrm{Y}_{0} \operatorname{coth}(\Psi 1) \mathrm{V}_{\mathrm{s}}-\mathrm{Y}_{0} \operatorname{csch}(\Psi 1) \mathrm{V}_{\mathrm{r}} \\
& \mathrm{I}_{\mathrm{r}}=-\mathrm{Y}_{0} \operatorname{csch}(\Psi 1) \mathrm{V}_{\mathrm{s}}+\mathrm{Y}_{0} \operatorname{coth}(\Psi 1) \mathrm{V}_{\mathrm{r}}
\end{aligned}
$$

Where $\Psi=(Z Y)^{1 / 2}, Y_{0}=(Y / Z)^{1 / 2}$ are the propagation constant and characteristic admittance of the line and computed as explained in [19]. Also, $\mathrm{V}_{\mathrm{s}}$ and $\mathrm{I}_{\mathrm{s}}$ represent, respectively, the voltage and current at the sending point of the line, and $\mathrm{V}_{\mathrm{r}}$ and $\mathrm{I}_{\mathrm{r}}$ are, respectively, the voltage and current at the receiving point of the line, and 1 denotes the length of transmission line. All these voltages are computed with respect to a point at infinite. Rewriting (3) and (4) in matrix form, we have

$$
\left[\begin{array}{l}
I_{s} \\
I_{r}
\end{array}\right]=\left[\begin{array}{ll}
A & B \\
C & D
\end{array}\right]\left[\begin{array}{c}
V_{s} \\
V_{r}
\end{array}\right]
$$

Where $\mathrm{A}=\mathrm{D}=\mathrm{Y}_{0} \operatorname{coth}(\Psi 1), \mathrm{B}=\mathrm{C}=-\mathrm{Y}_{0} \operatorname{csch}(\Psi 1)$. Eq. (5) is valid for each conductor in figure 1 . In figure 1 , there are two parallel conductors, i.e., (1-3) and (2-4). All of parallel conductors in a grid are called multi-conductor transmission line (MTL). Therefore, two MTLs are seen in this figure. If mutual coupling between parallel conductors is considered, Eq. (5) for each MTL is extended as bellow

$$
\begin{aligned}
& {\left[\begin{array}{c}
\mathrm{I}_{\mathrm{s} 1} \\
\mathrm{I}_{\mathrm{s} 3} \\
\mathrm{I}_{\mathrm{r} 1} \\
\mathrm{I}_{\mathrm{r} 3}
\end{array}\right]=\left[\begin{array}{llll}
\mathrm{A}_{11} & \mathrm{~A}_{12} & \mathrm{~B}_{11} & \mathrm{~B}_{12} \\
\mathrm{~A}_{21} & \mathrm{~A}_{22} & \mathrm{~B}_{21} & \mathrm{~B}_{22} \\
\mathrm{C}_{11} & \mathrm{C}_{12} & \mathrm{D}_{11} & \mathrm{D}_{12} \\
\mathrm{C}_{21} & \mathrm{C}_{22} & \mathrm{D}_{21} & \mathrm{D}_{22}
\end{array}\right]\left[\begin{array}{c}
\mathrm{V}_{\mathrm{s} 1} \\
\mathrm{~V}_{\mathrm{s} 3} \\
\mathrm{~V}_{\mathrm{r} 1} \\
\mathrm{~V}_{\mathrm{r} 3}
\end{array}\right]} \\
& {\left[\begin{array}{l}
\mathrm{I}_{\mathrm{s} 2} \\
\mathrm{I}_{\mathrm{s} 4} \\
\mathrm{I}_{\mathrm{r} 2} \\
\mathrm{I}_{\mathrm{r} 4}
\end{array}\right]=\left[\begin{array}{llll}
\mathrm{A}_{11} & \mathrm{~A}_{12} & \mathrm{~B}_{11} & \mathrm{~B}_{12} \\
\mathrm{~A}_{21} & \mathrm{~A}_{22} & \mathrm{~B}_{21} & \mathrm{~B}_{22} \\
\mathrm{C}_{11} & \mathrm{C}_{12} & \mathrm{D}_{11} & \mathrm{D}_{12} \\
\mathrm{C}_{21} & \mathrm{C}_{22} & \mathrm{D}_{21} & \mathrm{D}_{22}
\end{array}\right]\left[\begin{array}{c}
\mathrm{V}_{\mathrm{s} 2} \\
\mathrm{~V}_{\mathrm{s} 4} \\
\mathrm{~V}_{\mathrm{r} 2} \\
\mathrm{~V}_{\mathrm{r} 4}
\end{array}\right]}
\end{aligned}
$$

All elements in the above matrices are computed as reported in $[20,21]$. In general, $\mathrm{N}$ parallel conductors consist a MTL with a matrix of $(\mathrm{N}+2) \times(\mathrm{N}+2)$ size. In figure 1 , the two MTLs (1-3, and 2-4) are represented as two-port networks and connected as shown in figure 2 . In figure 2 , the lightning stroke is also represented as current source $I_{\mathrm{s}}$. Eqs. (6) and (7) can be combined as bellow

$\left[\begin{array}{l}\mathrm{I}_{\mathrm{s} 1} \\ \mathrm{I}_{\mathrm{s} 3} \\ \mathrm{I}_{\mathrm{r} 1} \\ \mathrm{I}_{\mathrm{r} 3} \\ \mathrm{I}_{\mathrm{s} 2}\end{array}\right]=\left[\begin{array}{llllllll}\mathrm{A}_{11} & \mathrm{~A}_{12} & \mathrm{~B}_{11} & \mathrm{~B}_{12} & & & & \\ \mathrm{~A}_{21} & \mathrm{~A}_{22} & \mathrm{~B}_{21} & \mathrm{~B}_{22} & & & 0 & \\ \mathrm{C}_{11} & \mathrm{C}_{12} & \mathrm{D}_{11} & \mathrm{D}_{12} & & & & \\ \mathrm{C}_{21} & \mathrm{C}_{22} & \mathrm{D}_{21} & \mathrm{D}_{22} & & & & \\ & & & & \mathrm{~A}_{11} & \mathrm{~A}_{12} & \mathrm{~B}_{11} & \mathrm{~B}_{12}\end{array}\right]\left[\begin{array}{c}\mathrm{V}_{\mathrm{s} 1} \\ \mathrm{~V}_{\mathrm{s} 3} \\ \mathrm{~V}_{\mathrm{r} 1} \\ \mathrm{~V}_{\mathrm{r} 3} \\ \mathrm{~V}_{\mathrm{s} 2} 8\end{array}\right.$

Eq. (8) can be more simplified if the following relations between sending and receiving voltages and currents of four conductors are used

$$
\begin{aligned}
& \mathrm{V}_{\mathrm{s} 1}=\mathrm{V}_{\mathrm{s} 4}, \mathrm{~V}_{\mathrm{r} 1}=\mathrm{V}_{\mathrm{s} 2}, \mathrm{~V}_{\mathrm{r} 2}=\mathrm{V}_{\mathrm{r} 3}, \mathrm{~V}_{\mathrm{s} 3}=\mathrm{V}_{\mathrm{r} 4} . \\
& \mathrm{I}_{\mathrm{s}}=\mathrm{I}_{\mathrm{s} 1}+\mathrm{I}_{\mathrm{s} 4}, \mathrm{I}_{\mathrm{r} 1}=-\mathrm{I}_{\mathrm{s} 2}, \mathrm{I}_{\mathrm{r} 2}=-\mathrm{I}_{\mathrm{r} 3}, \mathrm{I}_{\mathrm{s} 3}=-\mathrm{I}_{\mathrm{r} 4} .
\end{aligned}
$$

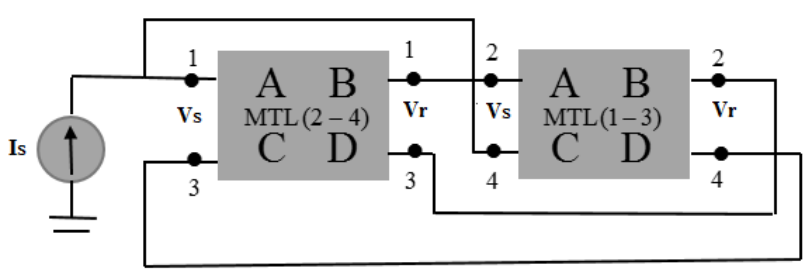

Figure 2: Representation of figure 1 as two-port networks.

By adding row 5 to 3,7 to 4,8 to 2 and 6 to 1 , as well as applying (9) and (10), the following equations are obtained: 


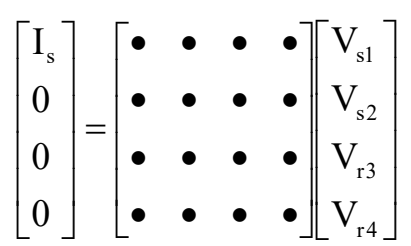

Finally

$$
\left[\begin{array}{c}
\mathrm{V}_{\mathrm{s} 1} \\
\mathrm{~V}_{\mathrm{s} 2} \\
\mathrm{~V}_{\mathrm{r} 3} \\
\mathrm{~V}_{\mathrm{r} 4}
\end{array}\right]=\left[\begin{array}{cccc}
\bullet & \bullet & \bullet & \bullet \\
\bullet & \bullet & \bullet & \bullet \\
\bullet & \bullet & \bullet & \bullet
\end{array}\right]^{-1}\left[\begin{array}{l}
\mathrm{I}_{\mathrm{s}} \\
0 \\
0 \\
0
\end{array}\right]
$$

Where "dots" in (12) indicate that these locations are filled with elements resulting from adding rows and columns. Therefore, once the lightning current is known, the sending voltage of $\mathrm{k}$-th conductor at $\mathrm{m}$-th frequency of lightning current, i.e., $\mathrm{V}_{\mathrm{sk}, \mathrm{m}}$ can be calculated from (12). Finally, the sending voltage of each conductor in time domain, $v_{s k}(t)$ is computed as follows,

$$
\mathrm{v}_{\mathrm{sk}}(\mathrm{t})=\sum_{\mathrm{m}=1}^{\mathrm{N}} \mathrm{V}_{\mathrm{sk}, \mathrm{m}} \cos \left(2 \pi \mathrm{f}_{\mathrm{m}} \mathrm{t}+\phi_{\mathrm{m}}\right)
$$

Where $\mathrm{N}$ denotes the total number of frequencies from spectral content of lightning current waveform. Evidently, since the modeling approach is in the frequency domain, frequency dependence of electrical parameters of soil (dispersion of soil) can be easily incorporated. Further information about the MTL in modeling general grounding grids of arbitrarily-numbered meshes is found in [19]. Figure 3 shows the block diagram of the MTL in transient analyses of grounding grids buried in dispersive soils.

\section{Numerical simulations and Verification}

In this section, the MTL is applied to different grounding grids published in literature, and its validity is investigated. Figure 4 shows a grounding grid buried in dispersive soil, which is center and corner-injected by a lightning current. The grounding grid is an equally spaced $d_{1} \times d_{2}$ square and the depth of the grid is $\mathrm{d}_{3}$.

The dispersion of soil in all examples investigated in this study is expressed by the formulae extracted by S. Visacro et al [22], i.e.

$$
\begin{aligned}
& \rho(f)=\rho_{0}\left(1+\left(1 \cdot 2 \cdot 10^{-6} \cdot \rho_{0}^{0.73}\right)(f-100)^{0.65}\right)^{-1} \\
& \varepsilon_{r}(f)=\left\{\begin{array}{lr}
192.2 & f \leq 10 \mathrm{kHz} \\
1.3+7 \cdot 6 \cdot 10^{3} . \mathrm{f}^{-0.4} & \mathrm{f} \geq 10 \mathrm{kHz}
\end{array}\right.
\end{aligned}
$$

Where $\rho(f)$ and $\varepsilon_{r}(f)$ express respectively frequency variations of resistivity and relative dielectric constant of soil. In (14) $\rho_{0}$ is low-frequency resistivity of soil.

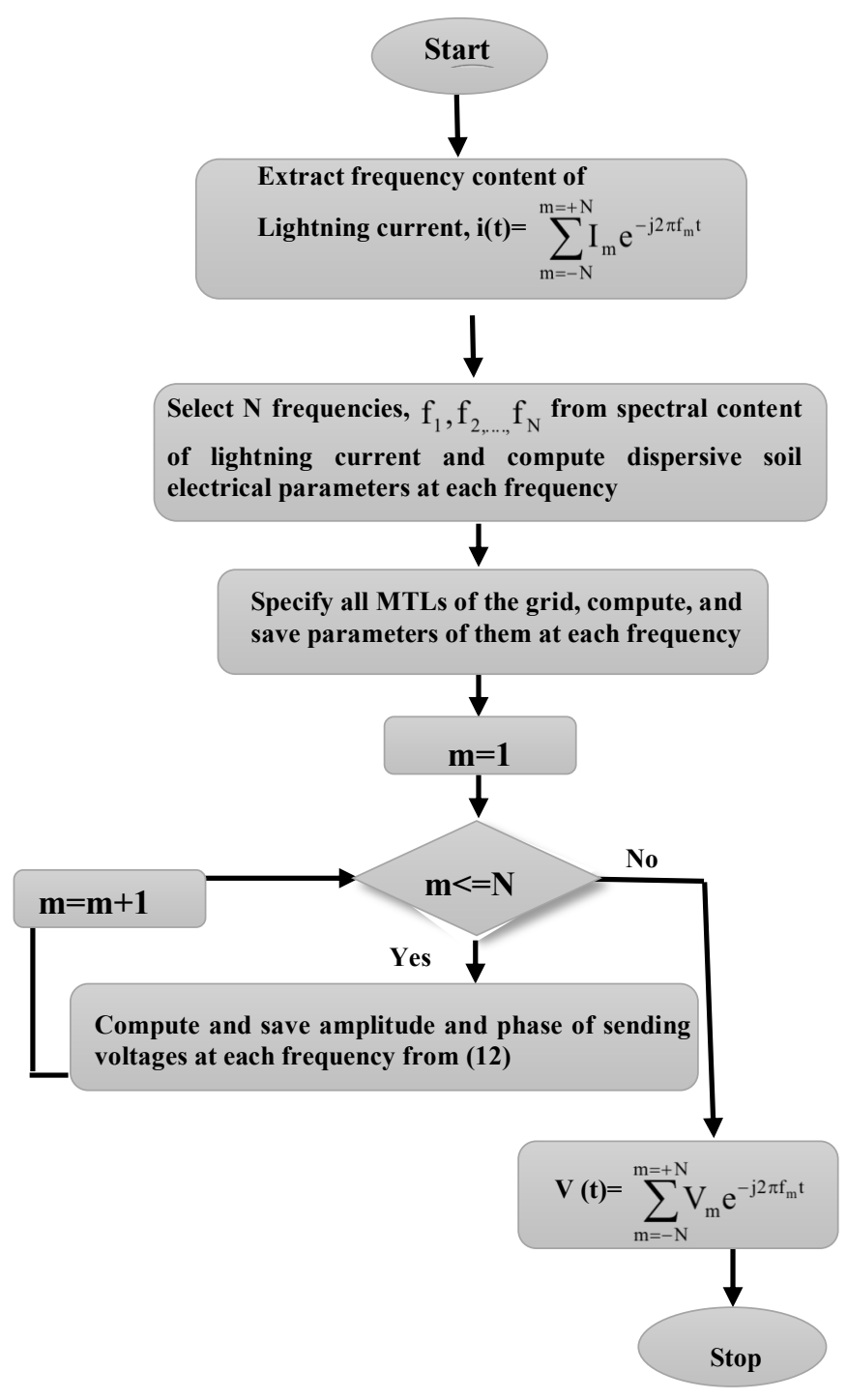

Figure 3: Flow chart of the MTL in dispersive soils.

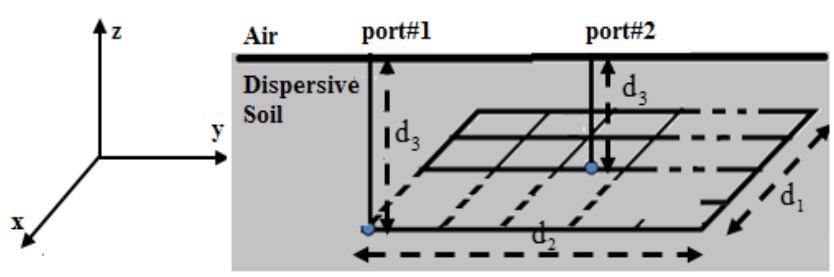

Figure 4: Scematic diagram of two-port grounding grid of arbitrarily-numbered meshes buried in lossy dispersive soil.

\section{A. Comparison with FEM [4]}

In the first example, a grounding grid from [4] with $\mathrm{d}_{1}=2 \mathrm{~m}$ , $\mathrm{d}_{2}=3 \mathrm{~m}$ and $\mathrm{d}_{3}=0.5 \mathrm{~m}$ is selected. Each mesh inside grid is a $1 \mathrm{~m} \times 1 \mathrm{~m}$ square. In this case, there are 5 independent MTLs, in which two MTLs are in ' $x$ ' direction, and three MTLs are in ' $y$ ' direction.

The electrical parameters of soil with low-frequency resistivity $\rho_{0}=1000 \Omega$.m are shown in figure 5 . As seen in this figure, for frequencies more than $10 \mathrm{KHz}$, the dispersion 
of soil cannot be disregarded. Such a grounding grid is only center-injected via two slow and fast current waves form namely first and subsequent stroke as shown in figure 6 .

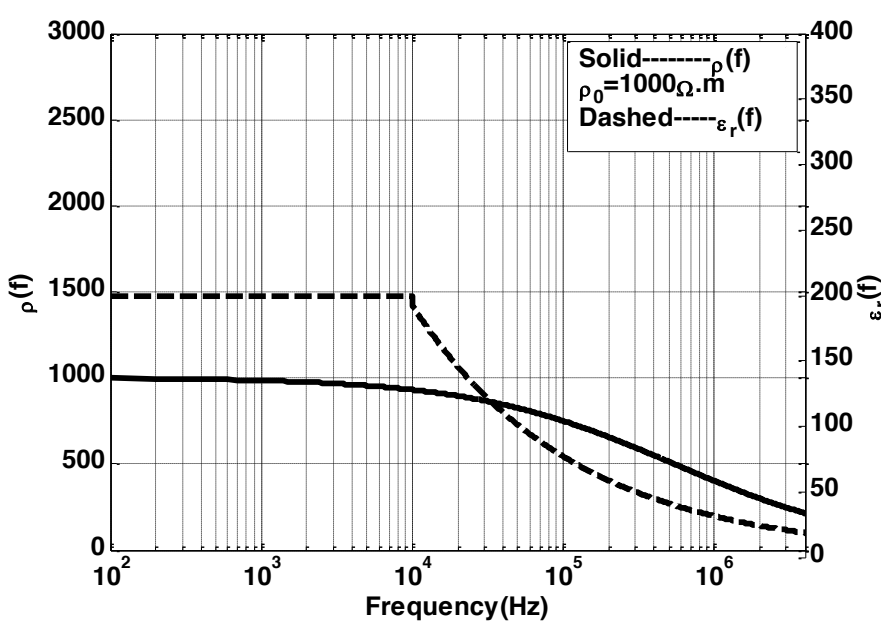

Figure 5: Frequency variation of electrical parameters of soil for low-frequency resistivity $\rho_{0}=1000 \Omega . . \mathrm{m}$.

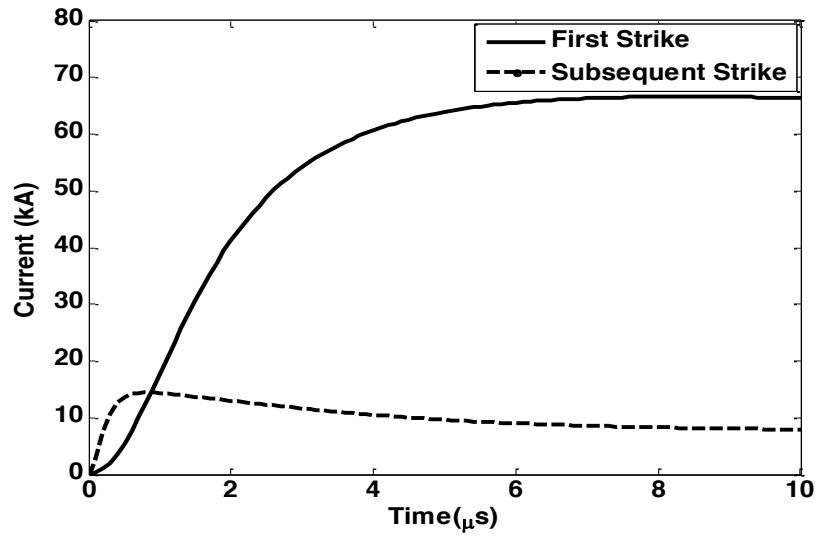

Figure 6: Two typical lightning current waveforms namely first and subsequent stroke used in the first example. Adapted from [4].

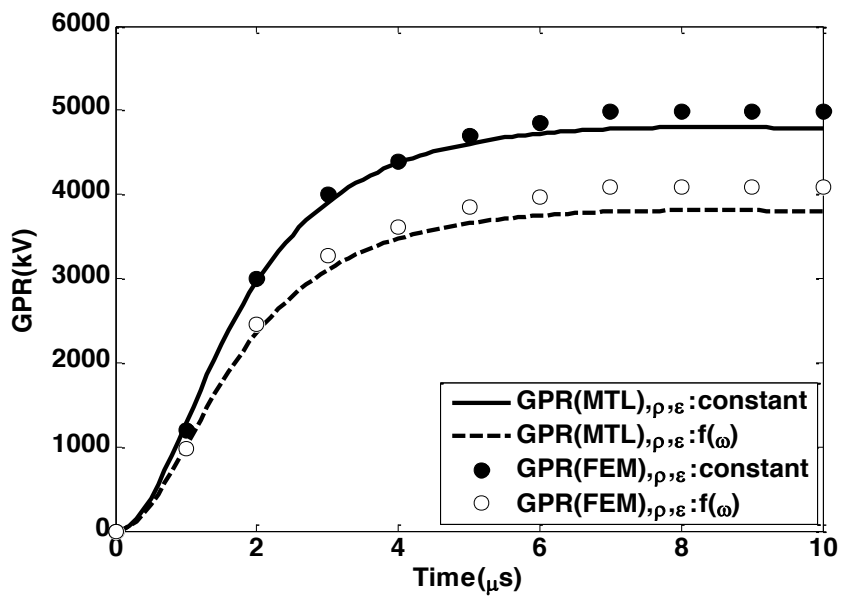

Figure 7: GPRs of grounding grid under first stroke current using MTL and comparision with FEM [4].

Without losing generality, in this study first stroke current is only investigated. Figure 7 shows the grounding potential rise (GPR) via MTL and compares with FEM in [4]. In this figure, two cases namely with and without considering dispersion of soil are compared. As shown in this figure, excellent agreement is achieved.

\section{B. Comparison with Experiment [10]}

In the second example, a corner-injected grid with $\mathrm{d}_{1}=16 \mathrm{~m}$ , $\mathrm{d}_{2}=20 \mathrm{~m}$ and $\mathrm{d}_{3}=0.5 \mathrm{~m}$ from [10] is selected. Each mesh inside grid is a $4 \mathrm{~m} \times 4 \mathrm{~m}$ square. There are nine independent MTLs, in which five MTLs are in ' $x$ ' direction, and four MTLs are in ' $y$ ' direction. In this example, the grid is also assumed to be dispersive and non dispersive with lowfrequency resistivity of $\rho_{0}=2000 \Omega . \mathrm{m}$. Frequency variations of electrical parametrs os soil in this case are shown in figure 8. The injected current in this example is shown in figure 9 which is injected only at grid corner. In figure 10, the simulated GPRs via MTL and measurement are shown and compared. Again good agreement is achieved. Note that a small error in maximum of GPRs may be due to inexact lightning current extracted from [10] and used in the simulation.

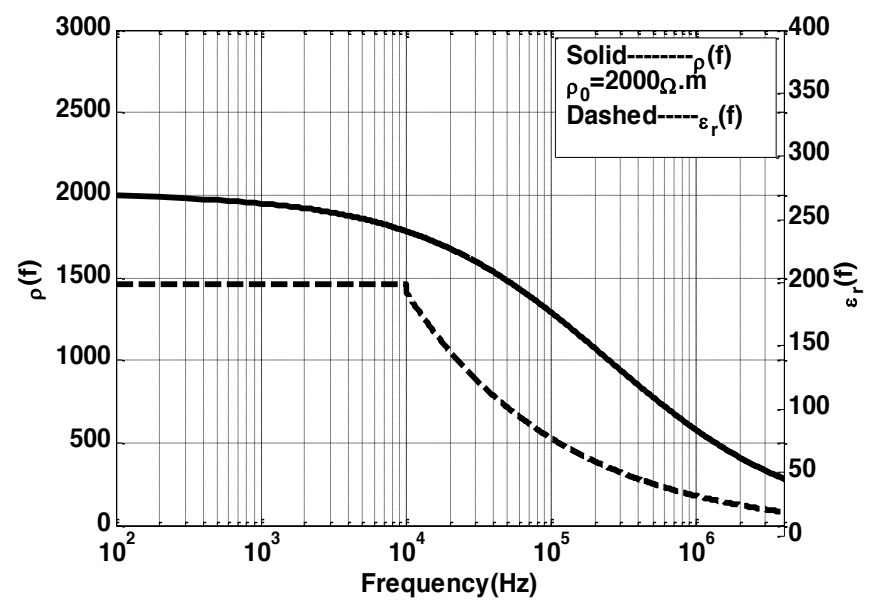

Figure 8: Frequency variation of electrical parameters of soil for low-frequency resistivity $\rho_{0}=2000 \Omega . \mathrm{m}$.

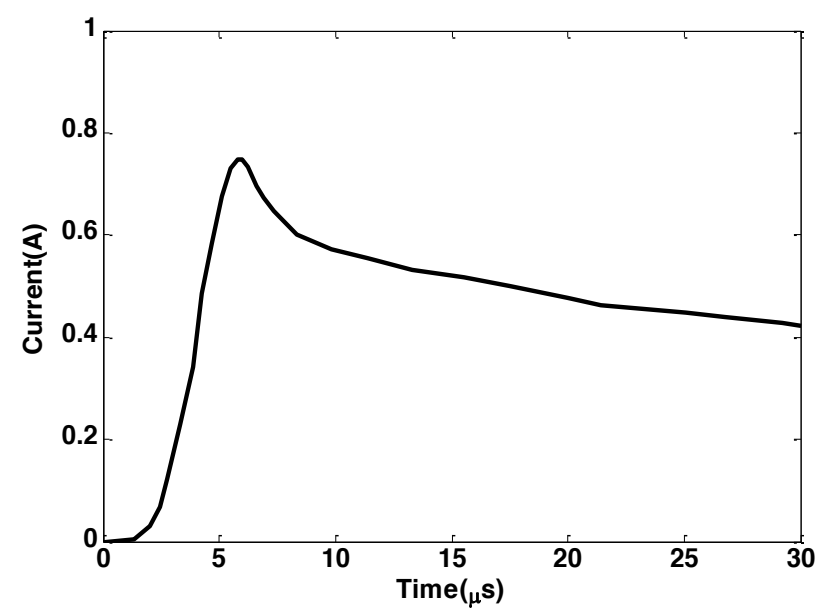

Figure 9: Measured lightning current waveforms with 4- $4 \mathrm{~s}$ front-time used in the second example. Adapted from [10]. 


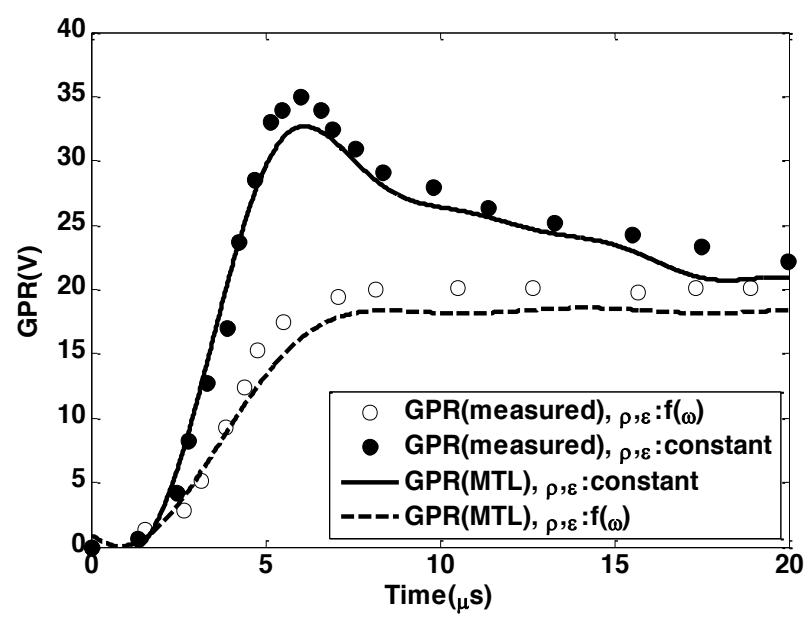

Figure 10: GPRs of grounding grid using MTL and comparision with measurement [10].

\section{Comparison with HEM [10]}

In the third example carried out by S. Visacro et al [10], a grounding grid with $\mathrm{d}_{1}=60 \mathrm{~m}, \mathrm{~d}_{2}=60 \mathrm{~m}$ and $\mathrm{d}_{3}=0.8 \mathrm{mis}$ selected. Each mesh inside grid is $5 \mathrm{~m} \times 5 \mathrm{~m}$ square. There are 24 independent MTLs, in which 12 MTLs are in ' $\mathrm{x}$ ' direction, and 12 MTLs are in ' $y$ ' direction.

In this case, frequency variations of the electrical parameters of soil with $\rho_{0}=3000 \Omega$..m are shown in figure 11. Comparison of figures 5,8 , and 11 show that when lowfrequency resistivity of soil is increased, frequency dependence of electrical parameters of soil is more considerable. Here the grid is subjected to a current as shown in figure 12 at its corner point. The simulated GPRs using MTL with and without considering dispersion of soil are shown in figure 13 and compared with the HEM ones [10]. Once more the results in figure 13 demonstrate the validity of the MTL.

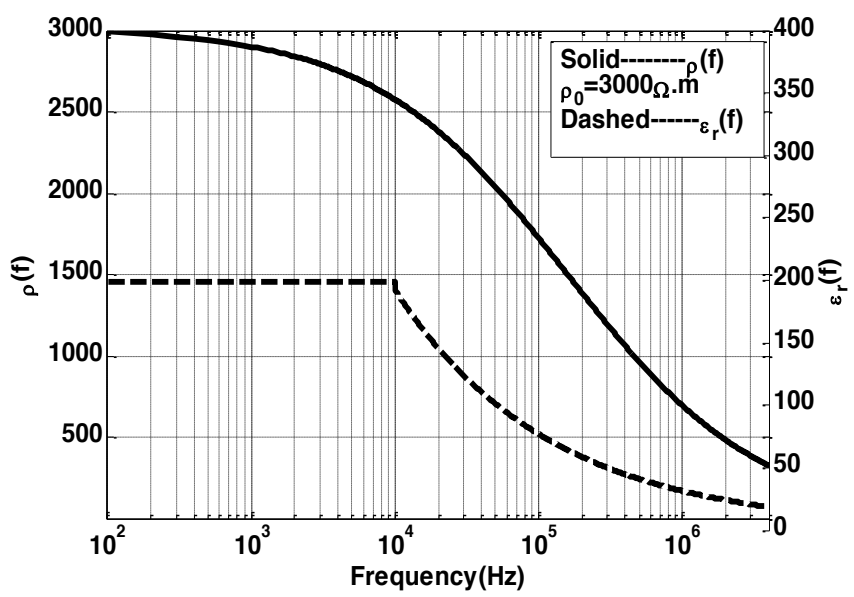

Figure 11: Frequency variation of electrical parameters of soil for low-frequency resistivity $\rho_{0}=3000 \Omega . . \mathrm{m}$.

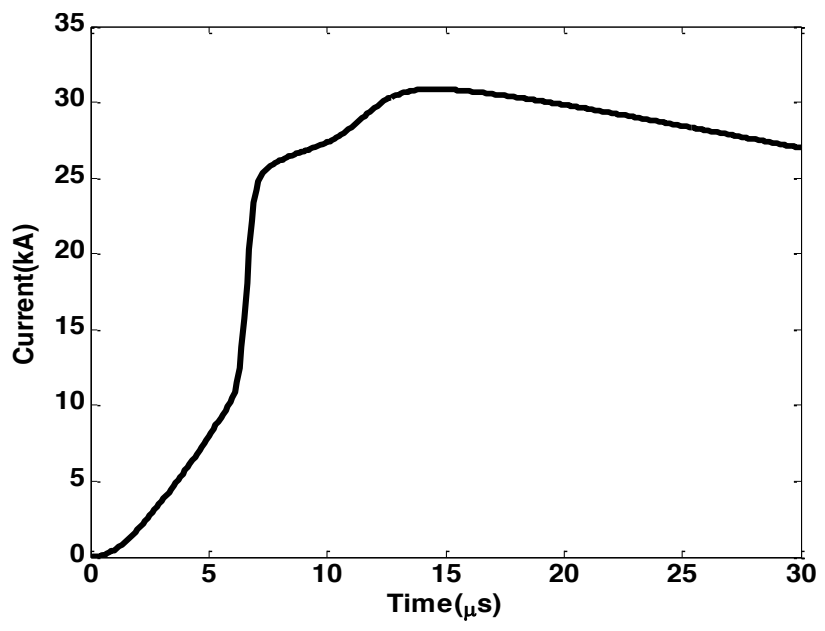

Figure 12: First stroke current used in the third example. adapted from [10].

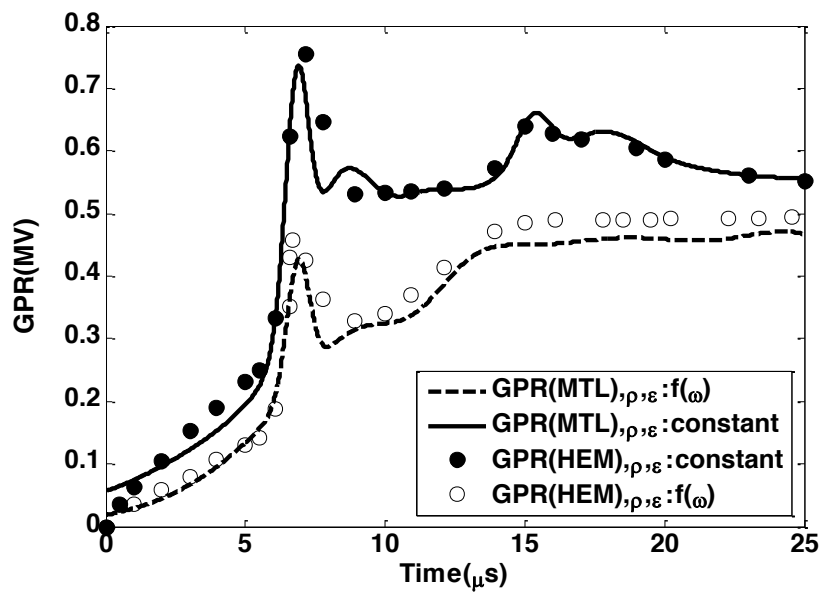

Figure 13: GPRs of grounding grid using MTL and comparision with HEM in [10].

To further show the accuracy of the MTL in comparison with the accurate models, a number of comparative data on the peak values of the GPRs and grounding resistances for the three examples are listed in table 1. The results in this table show good agreement with the ones in the published papers. The small differences in each situation in table I undershoot might be due to the numerical errors introduced through the Fourier series that is used to obtain the time domain waveform of the lightning currents.

Table 1. Comparison of GPRs and $\mathrm{R}$ of grounding grids for the different examples. The GPRs for the first and third examples are in MV, whereas for the second example in $\mathrm{V}$.

\begin{tabular}{c|cc|cc|cc}
\hline Case & \multicolumn{2}{|c|}{ Example 1 } & \multicolumn{2}{|c|}{ Example 2 } & \multicolumn{2}{|c}{ Example 3 } \\
\cline { 1 - 1 } Approach & \multirow{2}{*}{ MTL } & {$[4]$} & MTL & {$[10]$} & MTL & {$[10]$} \\
\hline GPR & 4.9 & 5 & 33 & 35 & 0.75 & 0.76 \\
\hline R $(\Omega)$ & 74 & 74.63 & 42 & 44.8 & 58 & 57.1
\end{tabular}




\section{Transient Analyses of Multi-Port Grids}

In this section to show capability of the MTL in multi-port grounding systems, the three example investigated in the previous section are again analyzed under center and corner injections simultaneously.

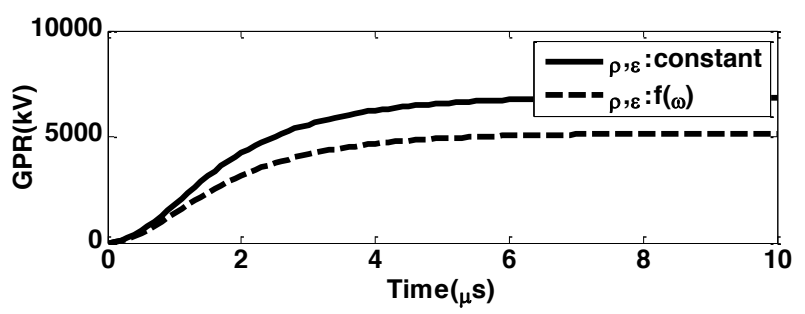

(a)

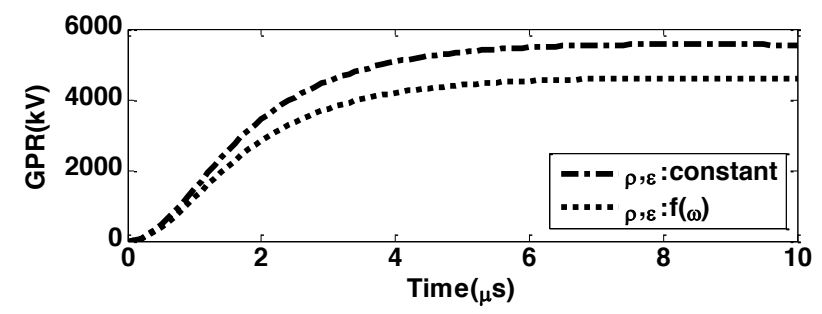

(b)

Figure 14: Transient voltage of grounding grid from the first example with two simultaneous injections at (a): port\#1 and (b): port\#2.

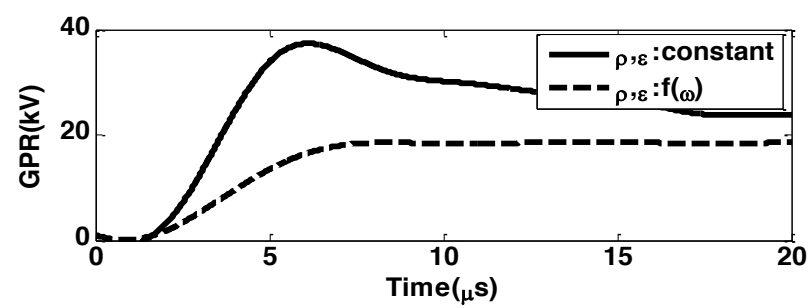

(a)

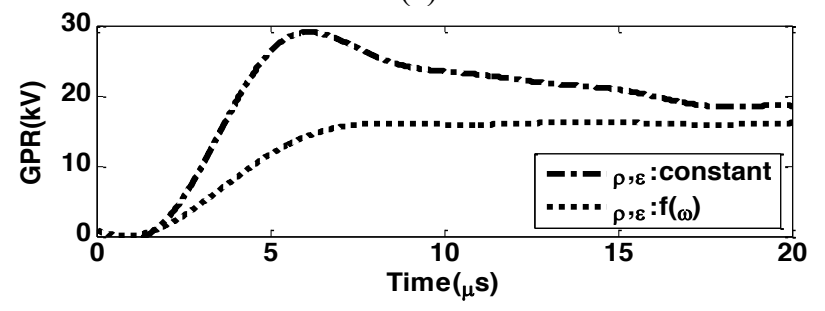

(b)

Figure 15: Transient voltage of grounding grid from the second example with two simultaneous injections at (a): port\#1 and (b): port\#2.

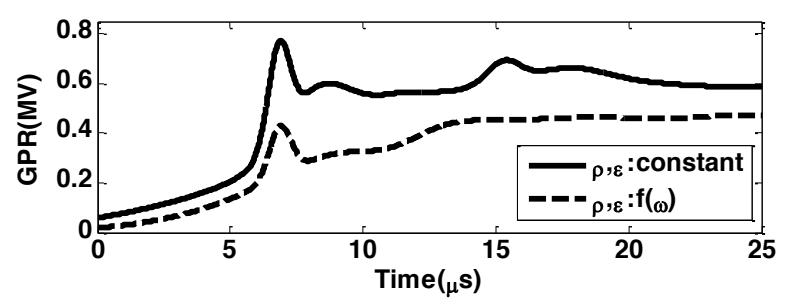

(a)

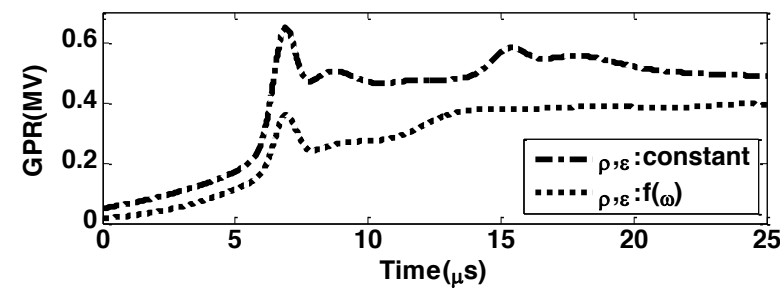

(b)

Figure 16: Transient voltage of grounding grid from the third example with two simultaneous injections at (a): port\#1 and (b): port\#2.

The GPRs for the first, second and third examples are shown in figures 14,15 , and 16 respectively. As seen in the three figures, both for dispersive and non-dispersive soil, the GPR in the case of corner injection (port\#1) is greater than that of the center-injection (port\#2). This is in consistent with the results in [23].

\section{Induced Voltage on the Soil Surface}

In the previous section via the MTL, once the voltages on each node are known, the currents in the grid conductors can be computed from (6). Accordingly, the difference between currents at the sending and receiving ends on each conductor determines the leakage currents into soil. For example, the leakage current for $\mathrm{i}$-th conductor is: $\mathrm{I}_{\mathrm{Li}}=\mathrm{I}_{\mathrm{si}}-\mathrm{I}_{\mathrm{ri}}$. This kind of current induces transient voltage on the soil surface which plays an important role for human safety and electrical and electronic equipment. With reference to [19], the induced voltage of a conductor of length $\mathrm{L}$ on the soil surface which is located along $\mathrm{X}$-axis is computed as following

$$
\mathrm{V}_{\mathrm{Q}}(\mathrm{x}, \mathrm{y}, \mathrm{z})=\sum_{\mathrm{i}=1}^{\mathrm{M}} \mathrm{R}_{\mathrm{m}}\left(\mathrm{x}_{1}, \mathrm{y}_{1}, \mathrm{z}_{1}\right)_{\mathrm{i}} \times \mathrm{I}_{\mathrm{Li}}
$$

Where $M$ is the total number of conductors, and $R_{m}$ is the transfer resistance between the $\mathrm{i}$-th conductor and the point of interest $\mathrm{Q}\left(\mathrm{x}_{1}, \mathrm{y}_{1}, \mathrm{z}_{1}\right)$ as bellow

$$
\mathrm{R}_{\mathrm{m}}=\frac{\rho}{8 \mathrm{~L} \pi}\left[\mathrm{F}_{1}\left(\mathrm{x}^{+}, A \mathrm{x}^{-}\right)-\mathrm{F}_{1}\left(\mathrm{x}^{-}, A \mathrm{x}^{-}\right)+\mathrm{F}_{1}\left(\mathrm{x}^{+}, A \mathrm{x}^{-}\right)-\mathrm{F}_{1}\left(\mathrm{x}^{+}, A \mathrm{x}^{+}\right)\right]
$$

Where

$$
\begin{aligned}
& F_{1}(t, u)=\ln (t+\sqrt{t+u}) \\
& x^{+}=x-x_{1}+L ; \quad x^{-}=x-x_{1}-L \\
& A x^{+}=\sqrt{\left(y-y_{1}\right)^{2}+\left(z+z_{1}\right)^{2}} \\
& A x^{-}=\sqrt{\left(y-y_{1}\right)^{2}+\left(z-z_{1}\right)^{2}}
\end{aligned}
$$

To the best our knowledge, there is no research on impact of dispersive soil on the induced voltage on the soil surface. Hence, the above formulae are applied on the three examples demonstared in the previous section. Figures 17, 18, and 19 show the lightning-induced voltage on the soil surface for the first, second, and third examples respectively at $\mathrm{t}=1 \mu \mathrm{s}$ 
under assumption of considering (C) and not considering (NC) soil dispersion. All the three figures show soil dispersion decreses the induced voltage on the soil surface. This is due to that in dispersive soils, soil conductivity is increased with respect to non-dispersive ones, and consequently electric field inside soil is more decresed.

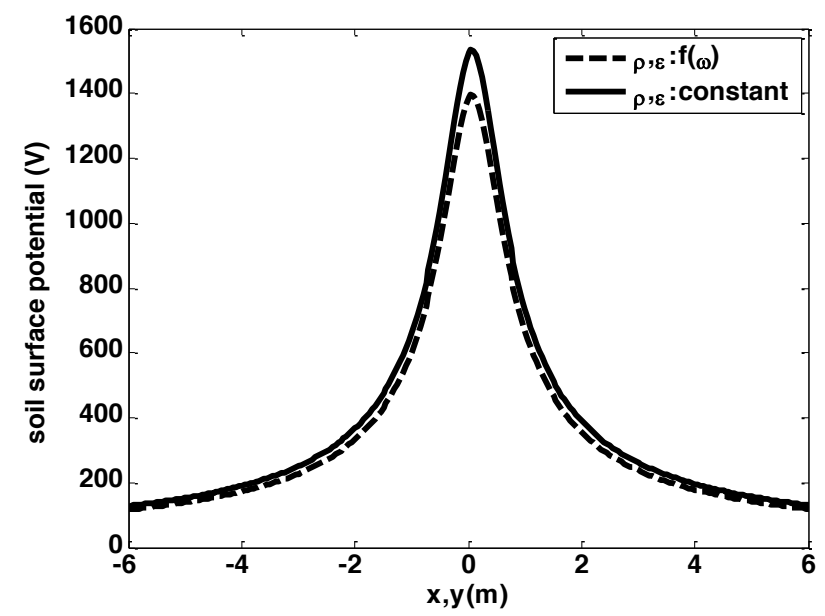

Figure 17: Induced voltage on the soil surface of grounding grid from example 1 .

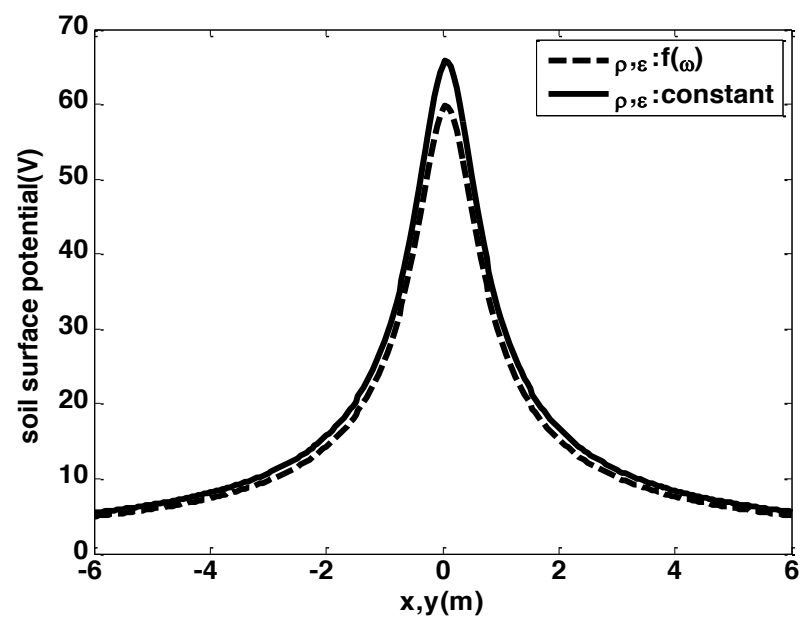

Figure 18: Induced voltage on the soil surface of grounding grid from example 2 .

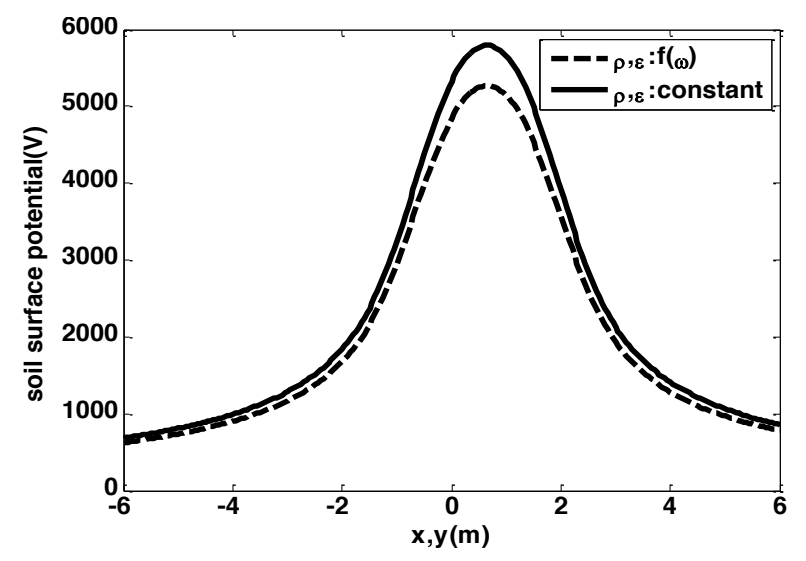

Figure 19: Induced voltage on the soil surface of grounding grid from example 3.
To further evaluate the effect of dispersion of soil, a sensivity analysis is carried out on the low-frequency resistivity of soil. To this aim, a reduction factor percentage (R.F\%) is defined as bellow

$$
\mathrm{R} . \mathrm{F} \%=\frac{\max (\mathrm{NC})-\max (\mathrm{C})}{\max (\mathrm{NC})} \times 100
$$

Table 2 shows the R.F\% for the three examples. This table shows that, when $\rho_{0}$ of soil is increased, the R.F\% is increased. This justifies the necessity of considering soil dispersion in the projectual analysis of grounding systems specially for soils of highly resistive soils.

Table :. The impact of disperssion of soil on the R.F\% for the different grounding grids.

\begin{tabular}{c|c|c|c}
\hline Case & Example 1 & Example 2 & Example 3 \\
\hline R.F\% & $12.8 \%$ & $13.2 \%$ & $13.5 \%$
\end{tabular}

\section{Computational Efficiency}

In this section, to show computational efficiency of the MTL, the approximate run-time of the MTL in computing GRRs at each frequency for the three examples are listed in table 3 which in comparison with accurate methods, i.e. FEM and HEM are very short. All computations are carried out on an Intel (R) Core (TM) i7-4702MQ CPU with 6GB of Ram.

Table 3: Computation time at each frequency through the MTL, FEM, and HEM for the three examples.

\begin{tabular}{c|c|c|c}
\hline Case & Example 1 & Example 2 & Example 3 \\
\cline { 1 - 1 } Approach & & & \\
\hline MTL & $0.12 \mathrm{sec}$ & $0.15 \mathrm{sec}$ & $0.2 \mathrm{sec}$ \\
\hline FEM & $12 \mathrm{~min}$ & $100 \mathrm{~min}$ & 3.5 hours \\
\hline HEM & $2 \mathrm{sec}$ & $5 \mathrm{sec}$ & $7 \mathrm{sec}$
\end{tabular}

\section{Conclusions}

In this study, an approximate approach called MTL was used for transient analyses of different grounding grids buried in dispersive soil. In this modeling approach, mutual coupling between parallel conductors inside grid is completely considered through defining two-port networks, whereas mutual coupling between collinear and echelon conductors is ignored. In addition, since the approach is in the frequency domain, dispersion of soil can be easily taken into account. The approach was applied on GPRs and induced voltages on soil surface for different grids, and the following key findings were achieved.

1-Simulation results on GPRs are in good agreement with full-wave and experimental results.

2-Impact of soil dispersion on the lightning-induced voltage on soil surface shows that soil dispersion in poorly conductive soils is of importance justifying necessity of including such an effect in projectual analyses, whereas in highly conductive ones it can be disregarded. 
3-The computational efficiency is considerably increased making it suitable in practical applications.

\section{References}

[1] IEEE Guide for Safety in AC Substation Grounding, IEEE Std. 80, January 2000.

[2] IEEE Recommended Practice for Grounding of Industrial and Commercial Power Systems (IEEE Green Book), IEEE Std. 142, 1991.

[3] D. Cavka, N. Mora, and F. Rashidi, A Comparison of Frequency-Dependence Soil Models: Application to the Analysis of Grounding systems, IEEE Transactions on Electromagnetic Compatibility, 56, 177-187, 2013.

[4] Majed Akbari, K. Sheshyekani, Mohammad Reza Alemi, The Effect of Frequency Dependence of Soil Electrical Parameters on the Lightning Performance of Grounding Systems, IEEE Transactions on Electromagnetic Compatibility, 55: 739-746, 2013.

[5] S. Visacro and Rafael Alipio, Frequency Dependence of Soil Parameters: Experimental Results, Predicting Formula and Influence on the Lightning Response of Grounding Electrodes, IEEE Transactions on Electromagnetic Compatibility, 27: 927-935, 2012.

[6] Rafael Alipio, S. Visacro, Modeling the Frequency Dependence of Electrical Parameters of Soil, IEEE Transactions on Electromagnetic Compatibility, 15: 1163-1171, 2014.

[7] Rafael Alipio, and S. Viscaro, Frequency Dependence of Soil Parameters: Effect on the Lightning Response of Grounding Electrodes, IEEE Transactions on Electromagnetic Compatibility, 55: 132-139, 2013.

[8] Rafael Alipio, and S. Visacro, Impulse Efficiency of Grounding Electrodes: Effect of Frequency-dependence Soil Parameters, IEEE Transactions on Power Delivery, 29: 716-723, 2014.

[9] S. Visacro, M. B. Guimaraes, and L. S. Araujo, Experimental Impulse Response of Grounding Grids, Electr, Power Syst. Res., 94: 92-98, 2013.

[10]S. Visacro, Rafael Alipio, Clever Pereira, Miguel Guimaraes, and Marcoa. O. Schroeder, Lightning Response of Grounding Grids: Simulated and Experimental Results, IEEE Transactions on Electromagnetic Compatibility, 57: 121-127, 2015.

[11]L. Grcev and F. Dawalibi, An electromagnetic model for transients in grounding systems, IEEE Trans. Power Del., 5: 1773-1781, 1990.

[12]M. Jin, the Finite Element Method in Electromagnetics, New York: Wiley, 2002.

[13] S. Visacro, A. Soares Jr, HEM: A model for Simulation of Lightning Related Engineering Problems, IEEE Transactions on Power Delivery, 20: 1026-1028, 2005.

[14] K. Sheshyekani, S. H. H. Sadeghi, R. Moini, F. Rachidi, Frequency-domain analysis of ground electrodes buried in an ionized soil when subjected to surge currents: A MoM-AOM approach, Electric Power System Research, 81: 290-296, 2011.

[15] J. He, Progress in Lightning Impulse Characteristics of Grounding Electrodes with Soil Ionization, IEEE
Transactions on Industry Applications, 51: 4924-4933, 2015.

[16]B. Zhang, J. Wu, Jinliang He, R. Zeng, Analysis of Transient Performance of Grounding System Considering Soil Ionization by the Time Domain Method, IEEE Transactions on Magnetics, 49: pp. 1837 1840, 2013.

[17] J. Wu, B. Zhang, J. He, and R. Zeng, A Comprehensive Approach for Transient Performance of Grounding System in the Time Domain, IEEE Transactions on Electromagnetic Compatibility, 57: 250-256, 2015.

[18] R. S. Bretas, Guilherme A. D. Dias, Marcos Tello, Dave W. P. Thomas, and Christos Christopoulos, The Transmission Line Modeling Method to Represent the Soil Ionization Phenomenon in Grounding Systems, IEEE Transactions on Magnetics, 50: 1163-1171, 2014.

[19] A. Jardines, J. L. Guardado, J. Torres, J. J. Chavez, M. Hernandez, A Multiconductor Transmission Line Model for Grounding Grid, Electrical Power and Energy Systems, 60: 24-33, 2014.

[20] Meliopoulos APS, Xia F, Joy EB, Cokkinides G, An Advanced Computer Model for Grounding Grid Analysis, IEEE Transaction on Power Delivery, 8: 1321, 1993.

[21]Meliopoulos APS, Power System Grounding and Transients: An Introduction. New York and Basel: Marcel Dekker: 1988.

[22] S. Visacro and Rafael Alipio, Frequency Dependence of Soil Parameters: Experimental Results, Predicting Formula and Influence on the Lightning Response of Grounding Electrodes, IEEE Transactions on Electromagnetic Compatibility, 27: 927-935, 2012.

[23]L. Crcev, "Lightning Surge efficiency of Grounding Grids, IEEE Transaction on Power Delivery, 26: 1692$1699,2011$. 